\title{
O Contrato de urgência sob o Regime Especial de Direito Administrativo (REDA) e seus efeitos para a Gestão de Pessoas no Funcionalismo Público
}

\author{
Cecília Luísa Rodrigues ${ }^{1}$; Evandro Vilas Boas Filho ${ }^{2}$
}

\begin{abstract}
Resumo: Em todas as organizações da sociedade há a necessidade de recrutar e selecionar pessoas para ocuparem os cargos e funções, sejam elas públicas ou privadas. O presente trabalho tem por objetivo analisar os efeitos que a priorização da contratação de pessoal através do Regime Especial de Direito Administrativo (REDA) em detrimento da realização de concurso público efetivo. Como objetivos específicos tem-se: caracterizar os principais conceitos relativos ao processo de captação e desenvolvimento de pessoas (recrutamento, seleção, treinamento e desenvolvimento de pessoas); apresentar a forma de admissão temporária por REDA no serviço público; refletir os impactos da utilização da contratação temporária para admissão de pessoal no funcionalismo público para o processo de gestão de pessoas. Para tanto, utilizou-se como metodologia a pesquisa bibliográfica e documental. Como resultado, percebe-se que o contrato temporário de caráter urgente no setor público traz consequências negativas do ponto de vista da gestão de pessoas, decorrente principalmente da contradição entre a necessidade de se possuir um quadro pessoal constantemente treinado e capacitado e da peculiaridade da não retenção desses profissionais sob esse regime.
\end{abstract}

Palavras-chaves: Gestão de Pessoas. Treinamento e Desenvolvimento de Pessoas. Regime Especial de Direito Administrativo (REDA)

\section{The Emergency Contract under the Special Regime of Administrative Law (SRAL) and its effects for the Management of People in Public Functioning}

\begin{abstract}
In all organizations of society there is a need to recruit and select people to fill the positions and functions, whether public or private. The aim of this study is to analyze the effects that prioritization in hiring personnel through the Special Administrative Law System (SRAL) in the detriment of the effective public tender. Specific objectives are: to characterize the main concepts related to the process of recruitment and development of people (recruitment, selection, training and development of people); present the form of temporary admission by SRAL in the public service; to reflect the impacts of the use of temporary employment for the admission of staff in the civil service for the people management process. For that, bibliographic and documentary research was used as methodology. As a result, it is perceived that the temporary contract of an urgent nature in the public sector has negative consequences from the point of view of people management, mainly due to the contradiction between the need to have a constantly trained staff and the peculiarity of the non-retention of these professionals under this regime.
\end{abstract}

Keywords: People management. Training and Development of People. Special Regime of Administrative Law (SRAL)

\footnotetext{
${ }^{1}$ Graduada em Administração pela Universidade Federal do Vale do São Francisco - UNIVASF; Pós-graduanda em Gestão Pública Municipal pela Universidade Federal do Vale do São Francisco-Univasf. cecilia-petro@ hotmail.com;

${ }^{2}$ Graduado em Administração de Empresas pela Universidade Estadual de Feira de Santana (UEFS), Pós-Graduado em Gestão de Pessoas pela Universidade Cândido Mendes (UCAM) e Graduando em Direito pela Universidade Federal da Bahia (UFBA) e Pós-Graduando em Gestão Pública pela Universidade do Estado da Bahia (UNEB)
} 


\section{Introdução}

Na gestão de pessoas, os processos de recrutamento e seleção de pessoal assumem importância indispensável ao bom andamento e ao aprimoramento das atividades exercidas por organizações públicas e privadas. Basicamente, a diferença entre essas organizações é a busca pelo resultado, ou seja, o lucro ou não. Enquanto esta procura maximizar o lucro, aquela busca atender a satisfação das necessidades coletivas através da prestação de serviços à sociedade.

No setor público esse processo assume formas diferenciadas em virtude da exigência legal de concurso público como forma de ingresso no serviço. Contudo, a Constituição da República Federativa do Brasil de 1988, também prevê a possibilidade de contratação de forma temporária e para cargos de provimento em comissão. Para que aquelas contratações temporárias possam acontecer dentro da legalidade, criou-se o Regime Especial de Direito Administrativo, mais conhecido como (REDA).

O presente artigo tem por objetivo, analisar os possíveis efeitos para a gestão de pessoas, decorrentes da priorização no setor público da realização de contrato temporário em detrimento da realização de concurso público para contratação de pessoal em regime efetivo.

Assim também, tem se como objetivos específicos: apresentar e caracterizar os principais conceitos relativos aos processos de recrutamento, seleção, treinamento e desenvolvimento de pessoas nas organizações; discutir a forma de admissão temporária por REDA no serviço público, ressaltando a importância do desenvolvimento pessoal para a qualificação de seu capital humano e consequente elevação no grau de excelência no desempenho das suas atividades fim; refletir os impactos da utilização da contratação temporária para admissão de pessoal no funcionalismo público para o processo de gestão de pessoas.

Desta forma, a pesquisa utilizar-se de estudos bibliográficos e documentais para o levantamento das informações necessárias ao levantamento das informações e compreensão conceitos a serem abordados e analisados sob a perspectiva dos contratos temporário REDA.

O presente trabalho está dividido nas seguintes partes: na primeira realiza-se uma revisão da literatura sobre os processos de captação e desenvolvimento de pessoas; na segunda parte apresenta-se os conceitos, as características e previsão legal acerca do Regime Especial de Direito Administrativo; por fim realiza-se a analise quanto aos possíveis impactos que forma de contratação temporária (REDA) podem decorrer para o serviço público quanto aos aspectos da gestão de pessoas. 


\section{Captação e Desenvolvimento de Pessoas nas Organizações}

$\mathrm{Na}$ atualidade o processo de captação e seleção de pessoas vem passando por constantes mudanças. As organizações estão mudando rapidamente e a tecnologia a cada dia em maior avanço. Diante disso, torna-se necessário que as organizações busquem cada vez mais qualificação profissional.

As organizações públicas esbarram na limitação constitucional, na qual prevê o artigo 37, inciso II, da CF de 1988, que estabelece que a posse em cargo ou emprego público depende de prévia aprovação em concurso público de provas ou de provas e títulos, conforme a natureza e a complexidade do cargo ou emprego, na forma prevista em lei, exceto as nomeações para cargo em comissão, que são declarados em lei de livre nomeação e exoneração.

Por outro lado, as organizações privadas captam e selecionam pessoas de acordo com o perfil estabelecido para a empresa, normalmente através de análise curricular e entrevistas, selecionando assim, o candidato que possua um perfil profissional mais qualificado e que esteja mais próximo às atribuições destinadas à função.

A área de Recursos Humanos passou por diversas fases ao longo do seu desenvolvimento, ela é composta por diversos subsistemas, onde cada um desenvolve um papel importante em todos os processos ligados aos RH. Da sua forma, Marras (2009, p.62) divide a ARH nos seguintes subsistemas: Recrutamento e seleção, Treinamento e desenvolvimento, Remuneração ou cargos e salários, Higiene e segurança do trabalho, Departamento Pessoal, Relações Trabalhistas, Serviços Gerais.

Para Oliveira (2005. P.19), no início do século XX os primeiros departamentos de RH controlavam, basicamente, as admissões e as demissões feitas pelos supervisores, dirigiam o departamento de pagamentos e administravam planos de benefícios. Quando a tecnologia em áreas como testes e entrevistas começou a surgir, o departamento de recursos humanos passou a desempenhar um papel maior na seleção, treinamento e na promoção de funcionários. Hoje, o papel da área de pessoal está mudando: de protetora, ela está se tornando planejadora e agente de mudanças. A metamorfose do departamento de recursos humanos em administração de recursos humanos reflete o fato de que nas organizações atuais, achatadas, competitivas e voltadas para o downsizing ${ }^{2}$, são os funcionários altamente treinados e comprometidos, e não as máquinas, que geralmente constituem a grande chave para a competitividade da empresa.

\footnotetext{
2 técnica utilizada na administração com a finalidade de eliminar os processos desnecessários que acabam engessando a tomada de decisões
} 


\section{Recrutamento}

Subsistema de RH é o responsável pela captação e triagem dos profissionais disponíveis no mercado de trabalho, como também o encaminhamento dos mesmos para as organizações onde irão atuar. As funções de recrutamento e seleção são bem diversificadas, por isso, dependendo do tamanho da organização, existe uma pessoa ou uma equipe responsável para desempenhar essas funções.

Sendo assim, Marras (2009, p.69), destaca recrutamento de pessoal como sendo: “[...] é uma atividade de responsabilidade do sistema de ARH que tem por finalidade a captação de recursos humanos interna e externamente à organização objetivando municiar o subsistema de seleção de pessoal no seu atendimento aos clientes".

Marras (2007, p.33) afirma ainda que o recrutamento deve ocorrer dentro do contexto do mercado de trabalho, que é o espaço onde ocorre a barganha entre as empresas e as pessoas, e o mercado de recursos humanos que é o conjunto de candidatos que buscam em emprego, este mercado envolve pessoas que estão dispostas a trabalhar e também as que já estão trabalhando. O recrutamento é feito a partir das necessidades de recursos humanos na organização e se divide em três etapas: pesquisa interna das necessidades, pesquisa interna do mercado e a definição das técnicas de recrutar a utilizar formando o planejamento de recrutamento.

Assim, o processo de recrutamento deve ser algo planejado dentro da organização para identificar as necessidades que existem dentro do mercado interno e a partir disso iniciar a busca também no mercado externo, buscando assim, os profissionais que melhor se encaixarem ao perfil estabelecido pela organização.

Para Chiavenato (2005, p.114), o planejamento de pessoal é o processo de decisão a respeito dos recursos humanos necessários para atingir os objetivos organizacionais em determinado período de tempo. O autor traz uma abordagem sobre o recrutamento interno, colocando que funciona através de oferta de promoções de cargo mais elevadas e, portanto, mais complexos e também apresenta vantagens e desvantagens como se pode observar a seguir: 
Quadro 1 - Vantagens e desvantagens do recrutamento interno

\begin{tabular}{|l|l|}
\hline Vantagens & Desvantagens \\
\hline $\begin{array}{l}\text { 1. Aproveita melhor o potencial humano } \\
\text { da organização; }\end{array}$ & $\begin{array}{l}\text { 1. Pode bloquear a entrada de novas ideias, } \\
\text { experiências e expectativas; }\end{array}$ \\
$\begin{array}{l}\text { 2. Motiva e encoraja o desenvolvimento } \\
\text { profissional dos atuais funcionários; }\end{array}$ & $\begin{array}{l}\text { 2. Facilita o conservantismo e favorece a } \\
\text { rotina atual; }\end{array}$ \\
$\begin{array}{l}\text { 3. Incentiva a permanência e fidelidade } \\
\text { dos funcionários á organização }\end{array}$ & $\begin{array}{l}\text { 3. Matem quase inalterado o atual } \\
\text { patrimônio humano da organização; }\end{array}$ \\
$\begin{array}{l}\text { 4. Ideal para a situação de estabilidade e } \\
\text { pouca mudança ambiental; }\end{array}$ & $\begin{array}{l}\text { 4. Ideal para empresas burocráticas e } \\
\text { mecanísticas; }\end{array}$ \\
$\begin{array}{l}\text { 5. Não requer socialização organizacional } \\
\text { de novos membros; }\end{array}$ & $\begin{array}{l}\text { 5. Matem e conserva a cultura } \\
\text { 6. Probabilidade de melhor seleção, pois }\end{array}$ \\
os candidatos são bem conhecidos; & 6. Funciona como um sistema fechado de \\
7. Custa financeiramente menos do que \\
fazer o recrutamento externo.
\end{tabular}

Fonte: Chiavenato, 2005, p. 114

Por outro lado, existe o recrutamento externo, que é quando as organizações captam recursos humanos que estejam disponíveis no mercado de trabalho e isso acontece normalmente quando não há dentro da organização pessoas com características inerentes ao cargo ou função disponibilizados.

Marras (2009, p.73) define recrutamento externo como "o processo de captação de recursos humanos no mercado de trabalho, com o objetivo de suprir uma necessidade da empresa no seu quadro de efetivos".

\section{Seleção}

Devido à grande competitividade no mercado de recursos humanos, selecionar pessoas tornou-se fundamental, uma vez que são elas que proporcionam produtividade, qualidade e competitividade para as organizações. A seleção compõe o processo de agregar valor que funciona após a escolha das técnicas de recrutamento que melhor atendam as necessidades organizacionais vividas no momento e parte do processo de seleção que é a escolha do profissional mais adequado para ocupar o cargo. (CARVALHO e NASCIMENTO, 1993, p. 114). 
O processo de seleção dentro de uma organização deve levar em consideração as exigências feitas ao cargo, bem como as características profissionais de cada pessoa para que, com isso, consiga fazer as melhores escolhas e alocar a pessoas certas no cargo certo.

França e Arellano (2002) afirmam que a seleção é a escolha dos candidatos mais adequados para a organização, dentre os candidatos recrutados, através de inúmeros instrumentos de análise, avaliação e comparação de dados.

De acordo com Robbins (2000), após recrutar um certo número de candidatos para um cargo vago, a tarefa agora é descobrir quem, dentre eles, seria o candidato mais bem qualificado para o cargo. Essa tarefa é bem complexa, mas, para auxiliar, existem pesquisas que ajudam na triagem e seleção dos candidatos.

Seleção de pessoal é uma atividade de responsabilidade do sistema de ARH, que tem por finalidade escolher, sob metodologia específica candidatos a emprego recebidos pelo setor de recrutamento para o atendimento das necessidades internas da empresa. (MARRAS, 2005, p.79).

Robbins (2000), afirma ainda que a seleção é um tipo de prognóstico. Através dela busca-se prever quais os candidatos que teriam sucesso caso fossem os escolhidos para ocupar a vaga em questão. Segundo ele, o candidato bem-sucedido seria o que desempenhasse bem mediante os critérios que a administração estabelece para avaliação de seu quadro de pessoal.

Segundo Marras (2005, p.79), todo o processo de seleção de pessoal é baseado na análise comparativa de dois campos, conforme listados nos quadros abaixo:

Quadro 2: Campos Do Processo Seletivo

\begin{tabular}{|l|l|}
\hline \multicolumn{1}{|c|}{ Exigências do cargo } & \multicolumn{1}{|c|}{ Características do candidato } \\
\hline $\begin{array}{l}\text { São as circunstâncias que o cargo exige do } \\
\text { profissional em termos de conhecimentos, } \\
\text { habilidades e atitudes para o bom desempenho } \\
\text { das funções. }\end{array}$ & $\begin{array}{l}\text { É conjunto de conhecimentos, habilidades e } \\
\text { atitudes que cada candidato possui para } \\
\text { desempenhar as suas tarefas. }\end{array}$ \\
\hline
\end{tabular}

Fonte: Marras, 2005. P. 79

Nesse contexto, Marras (2005) considera que, compõem-se trabalhos de prospecção ou coleta de informações e dados de cada indivíduo, em particular, na tentativa de conhecê-lo extrínseca e intrinsecamente. 


\title{
Treinamento e Desenvolvimento
}

Em meio ao dinamismo e às rápidas mudanças no macroambiente, o mercado de trabalho torna-se cada vez mais competitivo e seleto, por isso, as organizações são obrigadas a oferecer aos seus funcionários treinamentos que agregue valor a eles, tornando-os confiáveis e autoconfiantes e ao mesmo tempo garanta o sucesso organizacional. $\mathrm{O}$ treinamento é apenas um dos componentes desse processo de desenvolvimento que inclui as experiências que fortalecem e consolidam as características de seus colaboradores desejáveis em termos de seus papeis funcionais.

De acordo com Milkovich e Boudreau (2009, p.338) o treinamento é um processo sistemático para promover a aquisição de habilidades, regras, conceitos ou atitudes que resultem em uma melhoria da adequação entre características dos empregados e as exigências dos papeis funcionais. O treinamento é sem dúvida um grande negócio para a organização.

Para elucidar sobre o assunto Gil (2001, p.118) afirma que:

\begin{abstract}
O ambiente dinâmico das organizações requer o desenvolvimento de ações voltadas à constante capacitação das pessoas, com o objetivo de torná-las mais eficazes naquilo que fazem. Tanto é que, com frequência cada vez maior, as empresas vêm desenvolvendo programas de formação, treinamento e desenvolvimento de pessoas, a ponto de muitas empresas decidirem-se pela instalação não apenas de centros de treinamento e desenvolvimento, mas até mesmo de centros educacionais e universidades corporativas.
\end{abstract}

O constante incentivo ao conhecimento e à capacitação são os objetivos buscados pelas organizações ao se utilizar de treinamentos. Contudo, diferenciam-se o treinamento de desenvolvimento, para vários profissionais, o treinamento tem como objetivo os resultados imediatos, isto é, de curto prazo. Já o desenvolvimento capacita o indivíduo visando o aperfeiçoamento profissional e um bom desempenho futuro, porém os dois trabalham o profissional para ter resultados positivos. De acordo com Bohlander e Snell (2010, p.250):

O termo treinamento muitas vezes é usado de forma casual a fim de descrever praticamente qualquer esforço da empresa para estimular o aprendizado de seus membros. Muitos especialistas, entretanto, distinguem entre treinamento (mais focalizado e orientado para questões concernentes a desempenhar no curto prazo) e desenvolvimento (mais orientado para ampliar as habilidades dos indivíduos para futuras responsabilidades). 
Adquirir conhecimento tornou-se indispensável nas empresas modernas, quanto mais conhecimento, maior será de obter vantagem competitiva. Dessa forma, a capacitação e o treinamento são combinações importantes com os quais aumentam a base de habilidades e desempenho dos funcionários para obtenção do sucesso.

\section{Contrato Temporário de urgência sob o Regime Especial de Direito Administrativo (REDA)}

A contratação temporária através de Regime Especial de Direito Administrativo (REDA) deve ser para atendimento de necessidades excepcionais e de interesse público, por prazo determinado no âmbito da administração direta e indireta em todos os entes federativos. A Constituição Federal de 1988, em seu artigo 37, inciso IX estabelece que a regulamentação dessas contratações deva ser feita através de lei, ficando assim, cada ente federativo responsável pela elaboração de suas leis autorizadoras da contratação por tempo determinado, assim estados, distrito federal e municípios devem editar as leis que irão regular as contratações tanto no âmbito do poder executivo quanto do legislativo, devendo constar nessas leis os critérios e objetivos dessas contratações.

Para exemplificar melhor como se dá esse tipo de contratação, pegaremos como exemplo a legislação no âmbito da administração pública federal. Na União, o processo é regulamentado pela Lei $n^{\circ} 8.745 / 93$, a qual traz em seu artigo segundo as observâncias do que são considerados para a referida lei necessidades excepcionais:

\footnotetext{
Art. $2^{\circ}$ Considera-se necessidade temporária de excepcional Interesse público;

I - Assistência a situações de calamidade pública;

II - As emergências em saúde pública;

III- Realização de recenseamentos e outras pesquisas de natureza estatística efetuadas pela Fundação Instituto Brasileiro de Geografia e Estatística - IBGE;

IV - Admissão de professor substituto e professor visitante;

$\mathrm{V}$ - Admissão de professor e pesquisador visitante estrangeiro;

VI - Atividades;
}

A previsão legal estabelece que o recrutamento do pessoal a ser contratado deva ser realizado mediante Processo Seletivo Simplificado, estando este sujeito à ampla divulgação, inclusive no Diário Oficial da União. 
Essas contratações devem respeitar a alguns requisitos, conforme previstos no artigo 37, inciso II da Constituição Federal. Nesse sentido, o professor José dos Santos Carvalho Filho (1999) enumera pelo menos três pressupostos que devem estar presentes nas contratações temporárias para que estas sejam consideradas constitucionais. São elas: determinabilidade temporal da contratação, onde segundo ele os contratos com esses servidores devem sempre ter prazo determinado para serem encerrados; temporariedade da função, ou seja, a necessidade deve ser transitória, caso seja permanente, o estado deverá recrutar através dos demais regimes e excepcionalidade do interesse público, para que haja a necessidade de uma contratação através de contrato temporário, o interesse público deve ser excepcional, caso seja comum, não enseja esse tipo de contratação.

A Constituição Federal de 1988 trouxe expressamente as determinações de formas de ingresso ao serviço público da administração direta e indireta de todos os entes federativos do Brasil. Em seu capítulo VII no qual trata das disposições gerais inerentes à Administração Pública e à efetividade que o servidor público tem no serviço, após o ingresso através da aprovação em concurso público.

Nesse sentido, Hely Lopes Meirelles (2006, p.74), diz:

\begin{abstract}
Os servidores públicos em sentido estrito ou estatutário são os titulares de cargo público efetivo e em comissão, com regime jurídico estatutário geral ou peculiar e integrantes da Administração direta, das autarquias e das fundações públicas com personalidade de Direito Público. Tratando-se de cargo efetivo, seus titulares podem adquirir estabilidade e estarão sujeitos a regime peculiar de previdência social.
\end{abstract}

Ainda sobre a efetividade do cargo, José Afonso da Silva (2006, p. 697-698), faz a seguinte colocação:

Efetividade dá-se no cargo. É vínculo do funcionário ao cargo e constitui pressuposto da estabilidade, pois, só o servidor público pode adquiri-la. A estabilidade não se dá no cargo, mas no serviço público. É garantia do servidor, não atributo do cargo. A estabilidade é, assim, um direito que a constituição garante ao servidor público.

Notadamente, o concurso é a regra para o ingresso no serviço público, sendo considerada a forma com maior legitimidade e democracia de buscar pessoas para compor o quadro de pessoal na administração pública, o qual deve sempre respeitar os princípios constitucionais da legalidade, impessoalidade, moralidade, publicidade, eficiência e isonomia, pois todos são tratados da mesma forma, a finalidade é recrutar as pessoas mais capacitadas para o desempenho das atividades e atribuições relativas aos cargos públicos. Outro objetivo 
do concurso público é que os cargos públicos sejam ocupados por mérito e não por algo que seja diverso disso, como por exemplo, os interesses pessoais.

Por outro lado, a carta magna trouxe também exceções no que concerne ao recrutamento de pessoal para prestar o serviço público. Uma das exceções é para o cargo em comissão, declarado em lei de livre nomeação e exoneração, outra a contratação por tempo determinado para atendimento de excepcional interesse público, conforme já mencionada a previsão constitucional de interesse público e temporariedade.

Quanto aos cargos comissionados, a legislação diz que são de livre nomeação e exoneração por se tratar de pessoas indicadas, na maioria das vezes pelos chefes do executivo, e por se tratar de funções que requerem que os nomeados detenham a confiança de quem os indicou. Por sua vez, a contratação por tempo determinado através de Regime Especial de Direito Administrativo (REDA), deve cumprir alguns pressupostos, conforme mencionado no item anterior, bem como trazer possíveis desvantagens ao serviço público.

Por fim e não menos importante, temos os contratos por tempo determinado através do Regime Especial de Direito Administrativo (REDA), permitidos pela legislação para contratação de pessoal em caráter temporário para atendimento de necessidades temporárias e de excepcional interesse público. As pessoas contratadas pelo REDA não possuem vínculo efetivo com a administração pública, mas estarão sujeitos ao que preceitua a Lei no 8.429/92, conhecida como lei de Improbidade Administrativa, a qual traz em seu artigo segundo que se considera agente público:

[...] todo aquele que exerce, ainda que transitoriamente ou sem remuneração, por eleição, nomeação, designação, contratação ou qualquer outra forma de investidura ou vínculo, mandato, cargo, emprego ou função nas entidades mencionadas no artigo anterior.

Nesse sentido, toda pessoa que estiver no exercício de uma função pública será considerado agente público e estará sujeita as mesmas penalidades, independentemente de ser vínculo ser efetivo ou temporário.

Como vimos anteriormente, a contratação por tempo determinado é a exceção e não a regra, porém tem se tornado cada vez mais frequente entre os entes federativos. Vários podem ser os motivos para que isso aconteça, nos municípios é uma forma que se encontra de tentar burlar a legislação para que se coloque no quadro de pessoal pessoas próximas sem que ingressem por concurso público. 
Quanto ao regime de previdência, os contratados por tempo determinado estarão ligados ao regime geral de previdência social, conforme preconiza o parágrafo 13 do artigo 40 da Constituição Federal: “\$13 - Ao servidor ocupante, exclusivamente, de cargo em comissão declarado em lei de livre nomeação e exoneração bem como de outro cargo temporário ou de emprego público, aplica-se o regime geral de previdência social.” O servidor efetivo, por sua vez, estará sujeito ao regime próprio de previdência, caso o ente do qual faça parte o possua. $\mathrm{O}$ alto índice de contratação acaba por impactar diretamente os regimes próprios de previdência diante da prioridade que alguns municípios, principalmente, têm dado em relação ao REDA em detrimento da realização do concurso público.

\section{Efeitos do Contrato de urgência para a Gestão de Pessoas no Serviço Público}

Os processos de recrutamento e seleção são partes essenciais no processo de desenvolvimento em uma organização. Na esfera pública, esse processo contempla algumas peculiaridades e deve ser feito por meio de processo seletivo simplificado, no qual serão avaliados currículo e experiências profissionais dos candidatos, sendo dispensável o concurso público para essa modalidade. O recrutamento externo, a exemplo de um processo seletivo, traz à organização a possibilidade de inserção de novos talentos, habilidades profissionais, pessoas que trarão à organização uma nova cultura organizacional, aumentando assim, o capital humano da organização.

Por outro lado, esse processo pode afetar diretamente os funcionários que estejam há mais tempo dentro da organização, pois colocar pessoas novas dentro do ambiente pode transparecer conceder oportunidades a estranhos em detrimento dos que já fazem parte do quadro. Esse modelo exige um pouco mais no que se refere à socialização organizacional dos

novos funcionários e torna-se mais oneroso, demorado e inseguro se comparado ao recrutamento interno. (CHIAVENATO, 2009, p.79 - 96).

Nesse sentido, a contratação de pessoal através do contrato de urgência pode trazer impactos no que diz respeito à motivação dos servidores que já estão no serviço, mas também pode significar um redirecionamento do andamento do serviço, pessoas novas, habilidades novas, acarretam melhoria na qualidade do serviço ofertado.

A fase de selecionar pessoas possui certa complexidade, visto que a competitividade atual faz com que haja uma grande quantidade de pessoas que irão concorrer à mesma função 
que será disponibilizada no processo seletivo. Sendo assim, a organização deverá estabelecer para quais cargos serão disponibilizadas vagas e especificar quais sejam as atribuições pertinentes, bem como as competências que o candidato deverá ter para que ocupe a vaga. Nessas condições, as chances de contratar pessoas capacitadas serão maiores e, consequentemente, a organização pública terá maior vantagem competitiva.

Em contrapartida, há também os riscos inerentes a uma maior fragilidade para com o certame, decorrentes da possibilidade de uma rigorosidade menor no processo de seleção e admissão de pessoal, como por exemplo por via de análise curricular, bem como a subjetividade que a etapa de entrevista acarreta. Por isso, a máxima necessidade do estabelecimento de regras claras e objetivas quanto definição das competências exigidas aos candidatos e suas respectivas avaliações. Conforme preconiza França (2009. p. 34): “a seleção é a escolha dos candidatos mais adequados para a organização, dentre os candidatos recrutados, por meio de vários instrumentos de análise, avaliação e comparação de dados. " Devido à complexidade, faz-se necessário que o órgão ou empresa pública capacite pessoas para atuar no processo de recrutamento e seleção.

Após o recrutamento e seleção, torna-se necessário treinar e desenvolver essas pessoas para que elas possam aumentar seu potencial de desempenho e desenvolver suas competências e, assim, ampliarem suas capacidades e agregarem valor à organização. Nesse sentido, Parolin (2008, p.28) nos diz que:

O treinamento não se restringe apenas ao aumento de desempenho na função, tornando-se mais voltado para o desenvolvimento de competências que ampliem a capacidade da pessoa de agregar valor à organização para desempenho de funções futuras, priorizando os processos de aprendizagem individual, coletiva e organizacional.

Sendo assim, recrutar, selecionar e treinar pessoas é um processo longo, demorado e oneroso à organização, nesse sentido, os contratos de urgência tendem a ser mais complexos, pois apesar de sua extrema necessidade possuem nuances para a gestão de pessoas. Contratar pessoas para atendimento de necessidade de excepcional interesse público temporária requer um dispêndio de investimentos em treinamento e desenvolvimento cíclico e constante que se torna um ônus financeiro para o serviço público, visto que o desligamento desses profissionais do quadro de pessoal é certo e previsto.

Prejudica-se assim a formação de um quadro pessoal consolidada e fixa que conserve as habilidades e os conhecimentos que as organizações públicas precisam, através de seus 
colaboradores bem treinados e capacitados, para desempenharem suas funções e atingirem seus objetivos com qualidade e eficiência.

\section{Considerações Finais}

O trabalho mostrou uma análise sobre os processos de recrutamento, seleção e treinamento conforme entendimento constante na bibliografia apresentada, bem como contextualização no entendimento jurídico sobre esses processos para a administração pública.

Verificou-se também ao longo do desenvolvimento do trabalho que o processo de recrutamento externo possui desvantagens à organização, sendo oneroso aos cofres públicos, por exemplo, por se tratar de uma situação de tempo determinado.

O estudo aponta que possibilidade de contratação temporária pela Administração pública faz-se necessário visto que em algumas situações específicas exigem uma atuação rápida e efetiva dos gestores públicos para atendimento da necessidade coletiva, porém os contratos temporários através do REDA devem cumprir rigorosamente a previsão constitucional de excepcional interesse público e caráter temporário, visto que a regra para o ingresso no serviço público é o concurso. Além disso, tais funções não podem abranger o serviço fim da administração pública.

Sendo assim, constatou-se que o contrato temporário de caráter de urgência na administração pública pode trazer consequências negativas sob o ponto de vista da gestão de pessoas, o que é evidenciado na contradição existente entre a necessidade de possuir um quadro de pessoal treinado e capacitado e a rotatividade destes profissionais contratados na modalidade do REDA. A não retenção destes importantes colaboradores, reflete não só em custos financeiros, mas, principalmente, em prejuízos incalculáveis decorrentes da perda desse valioso capital humano.

\section{Referências}

BOHLANDER, George Bohlander, SNELL, Scott Snell. Administração de Recursos Humanos. -Tradução as $14^{\mathrm{a}}$ edição norte-americana, São Paulo: Cengage Learning, 2010. 
BRASIL. Constituição da República Federativa do Brasil de 1988. Disponível em: http://www.planalto.gov.br/ccivil_03/Constituicao/ConstituicaoCompilado.htm. Acesso em 16 abr. 2019.

BRASIL. Lei 8.429 de 02 de junho de 1992. Disponível em: http://www.planalto.gov.br/ccivil_03/leis/18429.htm. Acesso em 18 abr. 2019.

BRASIL. Lei 8.745 de 09 de dezembro de 1993. Disponível em: http://www.planalto.gov.br/ccivil_03/Leis/L8745compilada.htm.

CARVAlHO FILHO, José dos Santos. Manual de direito administrativo. 4. ed. Rio de Janeiro: Lúmen Júris, 1999.

CARVALHO, Antônio Vieira; NASCIMENTO Luiz Paulo. Administração de Recursos Humanos. Vol. 1. São Paulo: Pioneira, 1993.

CHIAVENATO, Idalberto. Desempenho humano nas empresas: como desenhar cargos e avaliar o desempenho para alcançar resultados. 6. ed. Barueri: Manole, 2005.

CHIAVENATO, Idalberto. Planejamento, recrutamento e seleção de pessoal: como agregar talentos à empresa. São Paulo: Manoele; 2009.

DA SILVA, José Afonso. Curso de Direito Constitucional Positivo. $27^{a}$ Edição - revista e atualizada. São Paulo: Editora Malheiros, 2006.

FRANÇA, Ana Cristina Limongi; ARELLANO, Eliete Bernal. Os processos de recrutamento e seleção. In: FLEURY, Maria Tereza Leme (Coord.). As pessoas na organização. 11. ed. São Paulo: Gente, 2002.

FRANÇA, Ana Cristina Limongi. Prática de Recursos Humanos - PRH: conceitos, ferramentas e procedimentos. São Paulo: Atlas, 2009.

GIL, Antônio Carlos. Gestão de Pessoas. São Paulo: Atlas, 2001.

MEIRELLES, Hely Lopes. Direito Administrativo Brasileiro. $27^{a}$ Edição. São Paulo: Editora Malheiros, 2006.

MARRAS, Jean Pierre. Administração de Recursos Humanos, $13^{a}$ ed. São Paulo: Saraiva, 2009.

MARRAS, Jean Pierre. Administração de Recursos Humanos: Do operacional ao Estratégico. $3^{\text {a }}$ ed. São Paulo: Futura, 2007.

MILKOVICH, George T., BOUDREAU, Jonh W. Administração de Recursos Humanos. São Paulo: Atlas, 2009.

OLIVEIRA, Luciana Sarkis de. Gestão de Pessoal: Métodos e Processos de Recrutamento e Seleção. Trabalho de conclusão de curso (Monografia). Faculdade de Ciências Sociais Aplicadas - FASA. Brasília, 2015. 
PAROLIN, S. R. H. Características organizacionais e espaço para a criatividade em organizações inovativas. Tese (Doutorado em Administração) - Faculdade de Economia, Administração e Contabilidade da Universidade de São Paulo, São Paulo. 2008.

ROBBINS, Stephen P. Administração: Mudanças e Perspectivas. São Paulo: Editora Saraiva, 2002.

\section{Como citar este artigo (Formato ABNT):}

RODRIGUES, Cecília Luísa; VILAS BOAS FILHO, Evandro. O Contrato de urgência sob o Regime Especial de Direito Administrativo (REDA) e seus efeitos para a Gestão de Pessoas no Funcionalismo Público. Id on Line Rev.Mult. Psic., 2019, vol.13, n.45, p. 734-749. ISSN: 1981-1179.

Recebido: 30/04/2019

Aceito 07/05/2019 